Article

\title{
Hybrid TODIM Method for Law Enforcement Possibility Evaluation of Judgment Debtor
}

\author{
Zhenyu Zhang ${ }^{1,2,3}{ }^{-}$, Jie Lin ${ }^{1, *}$, Huirong Zhang ${ }^{4}$, Shuangsheng $\mathrm{Wu}^{1}$ and Dapei Jiang ${ }^{5}$ \\ 1 School of Economics and Management, Tongii University, Shanghai 200092, China; \\ zhangzhenyu7@foxmail.com (Z.Z.); wss0810@tongji.edu.cn (S.W.) \\ 2 School of Automation, Nanjing University of Science \& Technology, Nanjing 210094, China \\ 3 Shanghai Municipal Engineering Design Institute (Group) Co., Ltd., Shanghai 200092, China \\ 4 School of Labor Relationship, Shandong Management University, Jinan 250357, China; zhr1975@126.com \\ $5 \quad$ SF Airlines Co., Ltd., Shenzhen 518128, China; jdpsky@163.com \\ * Correspondence: linjie@tongji.edu.cn
}

Received: 18 September 2020; Accepted: 15 October 2020; Published: 16 October 2020

check for updates

\begin{abstract}
The phenomenon of the judgment debtor evading the execution of legal documents and concealing his property by improper means has become increasingly prominent in China, which seriously affects the realization of the people's legitimate rights and interests. To protect the legitimate rights and interests of the people, it is necessary to study the law enforcement possibility evaluation of judgment debtors and quickly judge which judgment debtor is likely to complete the legal documents. A novel hybrid TODIM (an acronym in Portuguese for Interative Multi-criteria Decision Making) method for evaluating the law enforcement possibility of judgment debtors is developed. The main idea of the hybrid TODIM method is to obtain the relative possibility value of judgment debtors by comparing the attribute values between two judgment debtors and aggregating all the attributes' differences. The result shows that the hybrid TODIM method fully considers the psychological and behavioral factors of the law enforcement officers in the evaluation process. The evaluation result is more in line with the law enforcement officers' experience in handling execution cases. Compared with the hybrid TOPSIS (technique for order preference by similarity to ideal solution) method, the hybrid TODIM method is more suitable for solving the problem.
\end{abstract}

Keywords: hesitant fuzzy linguistic term sets (HFLTSs); TODIM; law enforcement; score measure; judgment debtor

\section{Introduction}

In recent years, the phenomenon of the judgment debtor evading the execution of legal documents and concealing his property by improper means has become increasingly prominent in China, which seriously affects the realization of the legitimate rights and interests of the people. The statistical data of the Supreme People's Court shows that during the period from 2016 to 2018, there were about 6 million execution cases per year on average, and the front-line law enforcement officers had to deal with about 150 execution cases every year. Front-line law enforcement officers are faced with tremendous work pressure. Therefore, research on the law enforcement possibility evaluation of judgment debtors is helpful to quickly judge which judgment debtor is likely to complete the legal documents, which relieves the work pressure of the law enforcement officers.

Law enforcement possibility evaluation of judgment debtors is, essentially, to judge whether the judgment debtors can implement the legal documents. By comparing and integrating the attributes of the judgment debtor, the relative law enforcement possibility of the judgment debtor to complement the legal documents can be calculated, which is helpful for law enforcement officers to focus on those who 
are more likely to complement the legal documents and improve the efficiency of handling execution cases. Assuming that many judgment debtors deliberately failed to execute the legal documents, attributes that affect the law enforcement possibility are extracted, such as the difference between annual income and expenditure, the amount of frozen property, the amount of recent malicious transfer or concealment of property, and credibility. Then, the attribute values of the judgment debtor are compared with each other, and the differences between the attribute values are synthesized to obtain the relative law enforcement possibility of these judgment debtors, find out the judgment debtor who is most likely to execute legal documents, and also identify the person who needs to be further tracked by the enforcement officers.

For evaluating the law enforcement possibility of judgment debtors, the law enforcement officers can only make a general judgment on the judgment debtor. However, in the actual evaluation process, it is necessary to judge and analyze whether the judgment debtor has the ability to execute the legal documents from multiple attributes, such as the amount of recently maliciously transferred or concealed property and their credibility. Therefore, the evaluation of the judgment debtors' law enforcement possibilities involves multi-attribute characteristics. The widely used multi-attribute assessment methods mainly include TOPSIS (technique for order preference by similarity to ideal solution) [1], LINMAP (linear programming technique for multidimensional analysis of preference) [2], ELECTRE (Elimination and Choice Translating Reality) [3,4], fuzzy graphs [5,6], and fuzzy mathematical programming, among others $[7,8]$. These methods are primarily based on the premise that the evaluator is completely rational, but the actual evaluation process needs to consider the psychological behavior of the evaluator. The most significant advantage of the TODIM method is that it can describe the psychological behavior of law enforcement officers in the evaluation process. Meanwhile, the values of the attributes in the evaluation include crisp numbers and hesitant fuzzy linguistic term sets (HFLTSs). Besides that, existing research focuses on some cases of criminal investigation and fraud identification by computer and information technology; there is no research for evaluating the law enforcement possibility of the judgment debtor.

Therefore, a novel hybrid TODIM method for evaluating the law enforcement possibility of the judgment debtor is developed. The main idea of the hybrid TODIM method to evaluate the law enforcement possibility of judgment debtors is to obtain the relative possibility value of judgment debtors by comparing the attribute values between two judgment debtors and aggregating the differences of all the attributes. Specifically, the gains and losses between two judgment debtors are calculated under different attributes, the dominance degree value of judgment debtors is given by aggregating the gains and losses of all the attributes, and the relative law enforcement possibility of the judgment debtor is calculated by the overall prospect value. The evaluation process is shown in Figure 1.

The contributions of the paper are as follows. Firstly, a novel hybrid TODIM framework for evaluating the possibility of law enforcement by the judgment debtor is developed, which helps law enforcement officers focus on the judgment debtor who can complement the legal document. Secondly, the values of the attributes in the developed hybrid TODIM method include crisp numbers and HFLTSs. Thirdly, a new score measure of hesitant fuzzy linguistic elements (HFLEs) is put forward to measure some attributes under hesitant fuzzy linguistic environments, such as the credibility of the judgment debtor. Fourthly, compared with the TOPSIS method, the TODIM method is more suitable for solving the problem.

The rest of the paper is organized as follows. Section 2 gives some literature review. Section 3 introduces some concepts of the TODIM method, HFLTSs, and some existing score measures. A novel score measure for HFLTSs is developed, and some properties on the developed score measure are discussed in Section 4. Based on the developed score measure, a hybrid TODIM framework for the law enforcement possibility evaluation of judgment debtors is put forward in Section 5. Section 6 presents a case study concerning the law enforcement possibility evaluation of judgment debtors. Some conclusions are remarked in Section 7. 


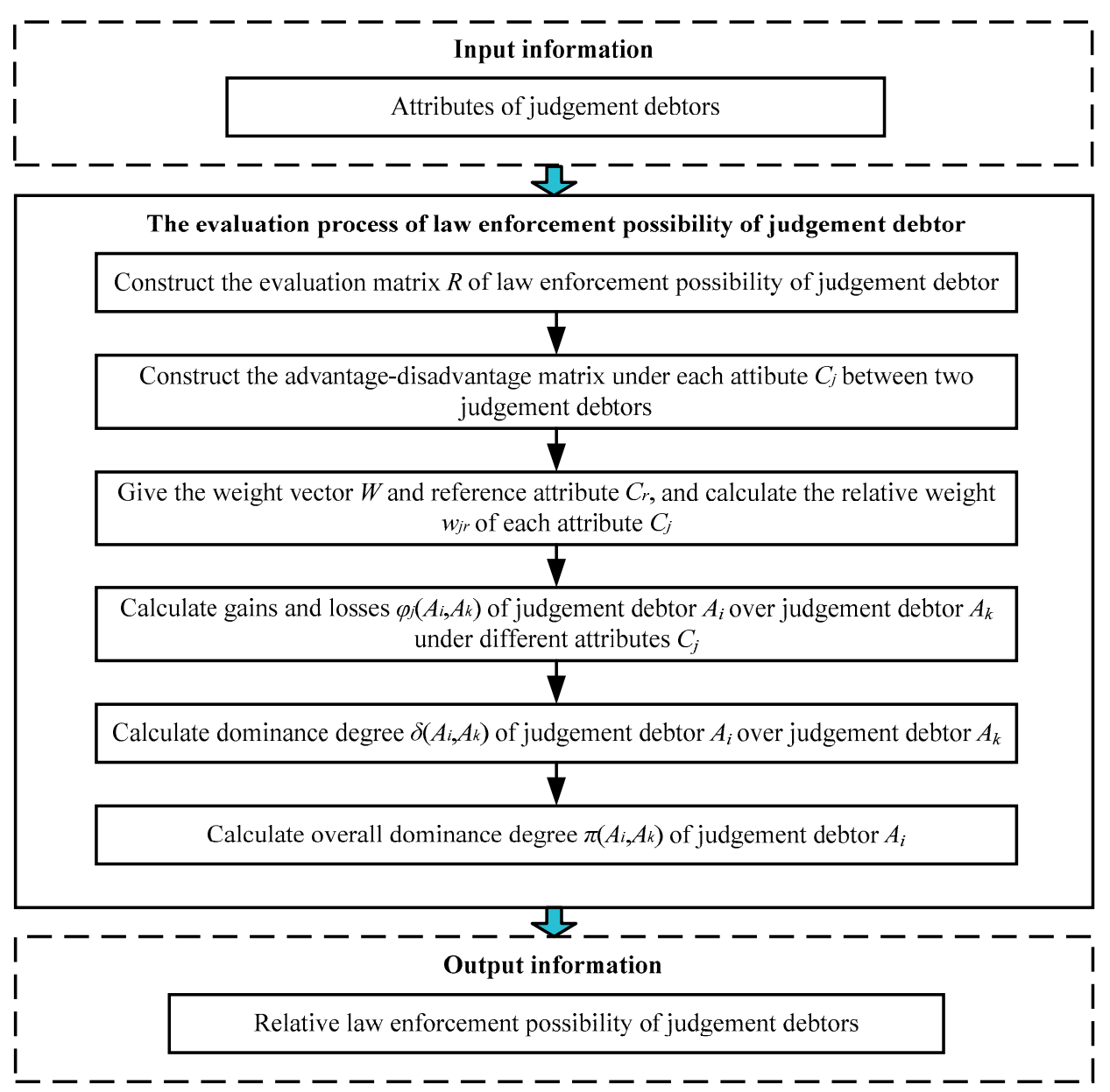

Figure 1. Flow chart of law enforcement possibility evaluation of judgment debtors based on the hybrid TODIM method.

\section{Literature Review}

Law enforcement possibility evaluation of judgment debtors involves multiple attributes. In essence, it can be regarded as a multi-attribute decision-making (MADM) problem. At present, for evaluating the execution ability of judgment debtors, law enforcement officers only make a general judgment on whether the judgment debtors complement the legal document. However, in the actual evaluation process, it is necessary to judge and analyze whether the judgment debtors execute the legal document from multiple attributes, such as the difference between annual income and expenditure, the amount of frozen property, the amount of recently maliciously transferred or concealed property, and credibility. The purpose is to judge who is more likely to complete the legal documents by comparing the attribute values between two judgment debtors. Therefore, the evaluation of the law enforcement possibility of judgment debtors involves multiple attributes.

The MADM method refers to the process of decision-makers using appropriate methods to sort the limited alternatives by aggregating the values of all attributes [9]. From analysis of the existing research, the MADM approach mainly has been divided into three categories: aggregation operator-based MADM, priority relationship-based MADM, and ideal solution-based MADM [10]. The most common aggregation operators include the weighted average operator [11], ordered weighted average operator [12,13], and ordered weighted geometric average operator [14]. The widely used priority relationship-based MADM methods are ELECTRE [3,4], PROMETHEE [15], QUALIFLEX (qualitative flexible multiple criteria method) [16-18], and their extended forms. The main idea of the ideal solution-based MADM method is to measure the distance between the alternative 
and the ideal solution or the negative ideal solution, which mainly includes TOPSIS [1], LINMAP [2], and VIKOR [19]. The above methods are mainly based on the premise that the decision-maker is completely rational. However, in the actual decision-making process, such as evaluating the law enforcement possibility of a judgment debtor, the influence of the decision-makers' psychological behavior should be considered.

The biggest advantage of the TODIM method is that it can describe the psychological behavior of law enforcement officers in the process of evaluation [20,21]. The MADM method has been widely used in various fields, such as natural gas company site selection [22], residential performance evaluation [23,24], emergency rescue plan selection [25], and green supplier selection [26-33]. Gomes et al. [27] used the advantages of the Choquet integral for solving the relationship between decision attributes, proposed a MADM method combining TODIM and the Choquet integral, and applied it to the problem of housing rent prediction. Considering that the traditional TODIM method cannot accurately describe the uncertainty and fuzziness of attribute values, Krohling et al. [28] put forward a hybrid method combining prospect theory and fuzzy numbers to deal with the risks and uncertainties in MADM problems and applied it to the risk assessment of oil spills at sea. Fan et al. [29] extended TODIM to the fuzzy environment and introduced random variables with a cumulative distribution function to propose a comprehensive, TODIM-based MADM method. Lourenzutti et al. [30] developed a new intuitionistic fuzzy distance measure and score measure and proposed an intuitionistic fuzzy TODIM method. Besides that, Lourenzutti et al. [31] also introduced the concept of Hellinger distance into the fuzzy TODIM method and used the concept of random dominance to deal with the probability distribution problem directly without any transformation of the model. Zhang et al. [32] analyzed the limitations on the existing TODIM method and put forward the stochastic, multi-objective, acceptability analysis-based TODIM approach. However, in the evaluation of judgment debtors' law enforcement possibilities, attribute values are mainly expressed by crisp numbers, fuzzy variables, HFLTSs, and other forms of data, so the TODIM method should be extended to the hesitant fuzzy linguistic environment.

So far, MADM methods have been extended to the hesitant fuzzy linguistic environment, such as TOPSIS, ELECTRE, and VIKOR. Berg et al. [34] proposed an improved hesitant fuzzy linguistic TOPSIS method, which provides two positive ideal separation matrices and negative ideal separation matrices, according to the envelope method, and has a good effect on solving MADM problems. Wei et al. [35] developed the generalized distance measure of the hesitant fuzzy linguistic term set, calculated the distance between alternatives and positive and negative ideal solutions, determined the important weight of evaluation index according to subjective and objective information, and proposed a hesitant fuzzy linguistic TOPSIS method. Chen and Hong [36] introduced the concept of an $\alpha$-cut set in hesitant fuzzy linguistic terminologies and transformed hesitant fuzzy linguistic information into an interval for MADM. Riera et al. [37] discussed the properties and advantages of discrete fuzzy numbers and constructed hesitant fuzzy linguistic decision models. Aiming at the decision-making problem in which attributes and weights are a hesitant fuzzy linguistic term set, Liao et al. [38] proposed the individual regret measure, compromise measure, and utility measure of hesitant fuzzy linguistics, and proposed a VIKOR method of hesitant fuzzy linguistics based on the new measure. Liu et al. [39] proposed a new envelope method based on existing research and applied it to the TOPSIS method. Wang et al. $[40,41]$ extended the ELECTRE method to a hesitant fuzzy linguistic environment, and it had a good effect in dealing with decision-making problems with the attribute value of a hesitant fuzzy linguistic term set. In recent years, some scholars have extended the TODIM method to hesitant fuzzy linguistic environments. Wang et al. [42] proposed the likelihood function of multiple HFLEs and applied it to the TODIM method to solve the decision-making problems of the limited rationality of decision-makers and the hesitancy of language evaluation information. Yu et al. [43] considered that the unbalanced language term set has a strong advantage over the balanced language term set in the actual decision-making process, gave the gain function and loss function of the unbalanced language term, and proposed the hesitant fuzzy linguistic TODIM method for the unbalanced term. The above 
hesitant fuzzy linguistic TODIM method compares the value of each attribute through the possibility degree, which is relatively complex. Wei et al. [44] proposed a new score measure, extended the classic TODIM method to a hesitant fuzzy linguistic environment, and used it to solve the actual telecom service provider selection problem. However, in the score measure calculation process, the effect of variance will be strengthened, resulting in the decision result being biased.

In the actual decision-making process, such as the law enforcement possibility evaluation of a judgment debtor, to consider the psychological and behavioral factors of the law enforcement officers in the evaluation, a hybrid TODIM framework is developed to evaluate the law enforcement possibility of the judgment debtor. The existing research usually uses the method of enveloping or transforming linguistic terms into fuzzy numbers to express a hesitant fuzzy linguistic term set. This way cannot reflect the original information completely and accurately and will cause the loss of original information. In the evaluation process, law enforcement officers may choose different linguistic terms when evaluating the credibility of the judgment debtor. The hesitant fuzzy linguistic term set has certain advantages in integrating the original evaluation information of the judgment debtor. At the same time, law enforcement officers are not entirely rational in the process of evaluating the law enforcement possibility of the judgment debtor. Therefore, it is essential to propose a method based on a hybrid TODIM method to assess the law enforcement possibility of judgment debtors.

\section{Preliminaries}

\subsection{TODIM Method}

The TODIM method is used to evaluate the law enforcement possibility of a judgment debtor. The most significant advantage of the TODIM method is that it can describe the psychological behavior of the law enforcement officers in the process of evaluating the judgment debtors' law enforcement possibilities. The parameters in the calculation process can be adjusted according to the risk preference of the law enforcement officers, and the evaluation results of the law enforcement possibilities of judgment debtors are in line with the preferences of the law enforcement officers. The evaluation steps of the traditional TODIM method are as follows [20,21].

Step 1: calculate the value $r_{i j}$ of the attributes under different alternatives, and construct the evaluation matrix $R=\left(r_{i j}\right)_{m \times n}$.

$$
R=\begin{gathered}
C_{1} \\
A_{1} \\
A_{2} \\
\ldots \\
\ldots \\
A_{m}
\end{gathered}\left(\begin{array}{ccccc}
r_{11} & r_{12} & \ldots & C_{n} \\
r_{21} & r_{22} & \ldots & r_{2 n} \\
\ldots & \ldots & \ldots & \ldots \\
r_{m 1} & r_{m 2} & \ldots & r_{m n}
\end{array}\right)_{m \times n}
$$

where $A_{1}, A_{2}, \ldots, A_{m}$ are $m$ alternatives, $C_{1}, C_{2}, \ldots, C_{n}$ are $n$ attributes, $r_{i j}$ represents the value of the attribute $C_{j}$ under the alternative $A_{i}$, and $\omega=\left(\omega_{1}, \omega_{2}, \ldots, \omega_{n}\right)^{T}$ is the weight of the attributes, and satisfies $\omega_{j} \in[0,1], \sum_{j=1}^{n} \omega_{j}=1$.

Step 2: regard the attribute with the maximum weight value as the reference attribute $C_{r}$, and calculate the relative weight value $\omega_{j r}$ of each attribute $C_{j}$ by Equation (1):

$$
\omega_{j r}=\omega_{j} / \omega_{r}, j=1,2, \ldots, n
$$

where $\omega_{j}$ is the weight value of the attribute $C_{j}$ and $\omega_{r}=\max \left\{\omega_{j} \mid j=1,2, \ldots, n\right\}$. 
Step 3: calculate the gains and losses $\phi_{j}\left(A_{i}, A_{k}\right)$ of alternative $A_{i}$ to alternative $A_{k}$ by Equation (2):

$$
\phi_{j}\left(A_{i}, A_{k}\right)=\left\{\begin{array}{cc}
\sqrt{\omega_{j k}\left(r_{i j}-r_{k j}\right) / \sum_{j=1}^{n} \omega_{j k},} & r_{i j}-r_{k j}>0 \\
0, & r_{i j}-r_{k j}=0 \\
-\frac{1}{\theta} \sqrt{\sum_{j=1}^{n} \omega_{j k}\left(r_{k j}-r_{i j}\right) / \omega_{j k},} & r_{i j}-r_{k j}<0
\end{array}\right.
$$

where the parameter $\theta$ is the attenuation factor of loss. Generally, $\theta>0$, and the value of the parameter $\theta$ depends on the specific decision-making problem. The higher the value of $\theta$, the lower the degree of loss aversion of decision-makers becomes. If the decision-maker is loss averse, facing the loss will produce greater psychological utility than an equal increment, which means that the decision-maker is more sensitive to loss. As shown in Equation (2), there are usually three situations:

1. If $r_{i j}-r_{k j}>0$, then $\phi_{j}\left(A_{i}, A_{k}\right)$ represents a gain;

2. If $r_{i j}-r_{k j}=0$, then $\phi_{j}\left(A_{i}, A_{k}\right)$ represents nil;

3. If $r_{i j}-r_{k j}<0$, then $\phi_{j}\left(A_{i}, A_{k}\right)$ represents a loss.

Step 4: calculate the dominance degree of alternative $A_{i}$ to alternative $A_{k}$ by Equation (3):

$$
\delta\left(A_{i}, A_{k}\right)=\sum_{j=1}^{n} \phi_{j}\left(A_{i}, A_{k}\right), i, k=1,2, \ldots, m
$$

Step 5: calculate the overall prospect value $\pi\left(A_{i}\right)(i=1,2, \ldots, m)$ of alternative $A_{i}$ by Equation (4):

$$
\pi\left(A_{i}\right)=\frac{\sum_{k=1}^{m} \delta\left(A_{i}, A_{k}\right)-\min _{i}\left\{\sum_{k=1}^{m} \delta\left(A_{i}, A_{k}\right)\right\}}{\max _{i}\left\{\sum_{k=1}^{m} \delta\left(A_{i}, A_{k}\right)\right\}-\min _{i}\left\{\sum_{k=1}^{m} \delta\left(A_{i}, A_{k}\right)\right\}}, i=1,2, \ldots, m
$$

Step 6: rank the alternative according to the overall prospect value $\pi\left(A_{i}\right)(i=1,2, \ldots, m)$, and obtain the optimal alternative.

\subsection{HFLTSS}

Firstly, some definitions of hesitant fuzzy sets and HFLTSs are introduced.

Definition 1. Let $x \in X$ [45]. A hesitant fuzzy set can be expressed by

$$
H=\{<x, h(x)>\mid x \in X\}
$$

where $h(x)$ is a set of some possible membership values. For convenience, $h=h(x)$ can be called the hesitant fuzzy element (HFE).

Definition 2. Let $x_{i} \in X, i=1,2, \ldots, N, S=\left\{s_{0}, s_{1}, \ldots, s_{g}\right\}$ be a linguistic term set [46]. A hesitant fuzzy linguistic term set on $X$ can be expressed by

$$
H_{S}=\left\{<x_{i}, h_{S}\left(x_{i}\right)>\mid x_{i} \in X\right\}
$$

where $h_{S}\left(x_{i}\right)$ is a set of some possible linguistic terms in $S$. For convenience, $h_{S}\left(x_{i}\right)$ can be called the HFLE. 
In the process of law enforcement possibility evaluation, the score measure of HFLEs and its corresponding ranking method play a crucial role in constructing the advantage-disadvantage matrix. Now, the score measures of HFLEs and their corresponding ranking method are introduced.

The ranking of HFLEs is essentially based on the score measure, which maps HFLEs into crisp numbers. According to the existing research on score measures of HFLEs and their corresponding ranking methods, they have been divided into the arithmetic ranking method and the non-arithmetic ranking method. For arithmetic ranking methods, Liao and $\mathrm{Xu}$ [38] proposed a score measure of HFLEs and its ranking method based on the statistical mean-variance model. The ranking results can only be obtained through multiple calculations. For the non-arithmetic ranking method, Wei and Ren [44] introduced the concept of variance in the score measure. Meanwhile, Liao and Qin [47] introduced the concept of hesitancy and proposed a new score measure, respectively. The ranking results only need to be achieved in one step, which improves the operation efficiency.

Next, the existing hesitant fuzzy linguistic score measures and the corresponding ranking methods are summarized, and a comparative analysis is made.

Definition 3. Let $S=\left\{s_{0}, s_{1}, \ldots, s_{g}\right\}$ be a linguistic term set (LTS), $h_{S}=\left\{s_{\delta_{l}} \mid s_{\delta_{l}} \in S, l=1,2, \ldots, L\right\}$ be an HFLE, and $h_{\gamma}=\{\gamma \mid \gamma \in[0,1]\}$ be a hesitant fuzzy element [48]. The equivalent information of linguistic variables $s_{\delta_{l}}$ can be expressed by the membership value $\gamma$ by the function $\Delta$ :

$$
\begin{gathered}
\Delta:[0, g] \rightarrow[0,1], \Delta\left(s_{\delta_{l}}\right)=\delta_{l} / g=\gamma \\
\Delta:[0, g] \rightarrow[0,1], \Delta\left(h_{S}\right)=\left\{\Delta\left(s_{\delta_{l}}\right)=\delta_{l} / g\right\}=h_{\gamma}
\end{gathered}
$$

Therefore, the membership value $\gamma$ can also be expressed by the linguistic variables $s_{\delta_{l}}$ obtained from the inverse function $\Delta^{-1}$ :

$$
\begin{gathered}
\Delta^{-1}:[0,1] \rightarrow[0, g], \Delta^{-1}(\gamma)=s_{\delta_{l} / g \times g}=s_{\delta_{l}} \\
\Delta^{-1}:[0,1] \rightarrow[0, g], \Delta^{-1}\left(h_{\gamma}\right)=\left\{\Delta^{-1}(\gamma)=s_{\delta_{l} / g \times g}\right\}=s_{\delta_{l}}
\end{gathered}
$$

Similar to the concepts of statistical mean and variance, Liao and $\mathrm{Xu}$ [38] proposed a ranking method based on the score measure of HFLEs. In Liao and Xu's method, ranking the HFLEs is based on the score and variance of the HFLEs. The higher the score, the higher the ranking. When the two HFLEs have the same score, the smaller the variance, the higher the ranking. The score measures and variance functions of HFLEs are defined as follows.

Definition 4. Let $h_{S}=\left\{s_{\delta_{l}} \mid s_{\delta_{l}} \in S, l=1,2, \ldots, L\right\}$ be an HFLE, $\delta_{l}$ represent the subscript of the lth linguistic term in $h_{S}$, and $L$ be the number of linguistic terms in $h_{S}[38]$. The score measure and variance function are then defined as

$$
\begin{gathered}
\rho_{1}\left(h_{S}\right)=\frac{1}{L} \sum_{l=1}^{L} \Delta\left(s_{\delta_{l}}\right) \\
\sigma\left(h_{S}\right)=\frac{1}{L} \sqrt{\sum_{l=1}^{L}\left(\Delta\left(s_{\delta_{l}}\right)-\rho_{1}\left(h_{S}\right)\right)^{2}}
\end{gathered}
$$

Therefore, for two HFLEs $h_{S}^{1}$ and $h_{S}^{2}, \rho_{1}\left(h_{S}^{1}\right)$ and $\rho_{1}\left(h_{S}^{2}\right)$ are the scores of $h_{S}^{1}$ and $h_{S}^{2}$, respectively, and $\sigma\left(h_{S}^{1}\right)$ and $\sigma\left(h_{S}^{2}\right)$ are the variances of $h_{S}^{1}$ and $h_{S}^{2}$, respectively. The ranking method is represented as 1. If $\rho_{1}\left(h_{S}^{1}\right)>\rho_{1}\left(h_{S}^{2}\right)$, then $h_{S}^{1}>h_{S}^{2}$; 
2. If $\rho_{1}\left(h_{S}^{1}\right)=\rho_{1}\left(h_{S}^{2}\right)$, then
a. If $\sigma\left(h_{S}^{1}\right)<\sigma\left(h_{S}^{2}\right)$, then $h_{S}^{1}>h_{S}^{2}$;
b. If $\sigma\left(h_{S}^{1}\right)=\sigma\left(h_{S}^{2}\right)$, then $h_{S}^{1} \sim h_{S}^{2}$.

Example 1. Let $S=\left\{s_{0}, s_{1}, s_{2}, s_{3}, s_{4}, s_{5}, s_{6}\right\}$ be the LTS and $h_{S}^{1}=\left\{s_{2}, s_{4}\right\}, h_{S}^{2}=\left\{s_{3}\right\}$, and $h_{S}^{3}=\left\{s_{1}, s_{3}, s_{5}\right\}$ be three HFLEs.

$$
\begin{gathered}
\rho_{1}\left(h_{S}^{1}\right)=0.5 \\
\rho_{1}\left(h_{S}^{2}\right)=0.5 \\
\rho_{1}\left(h_{S}^{3}\right)=0.5 \\
\sigma\left(h_{S}^{1}\right)=0.1179 \\
\sigma\left(h_{S}^{2}\right)=0 \\
\sigma\left(h_{S}^{3}\right)=0.1571
\end{gathered}
$$

Therefore, the sort result is $h_{S}^{2}>h_{S}^{1}>h_{S}^{3}$. If the method only depends on the score measure, it can't distinguish and rank the three HFLEs. Only by introducing the variance function can the ranking problem be solved effectively. Although the ranking method proposed by Liao and $\mathrm{Xu}$ [38] is effective in comparing the HFLEs, it will make the decision-making process more time-consuming since, in the decision-making process, it needs many steps and even needs to add other rules to complete the sorting.

To improve the operation efficiency, Wei and Ren [44] proposed a new score measure and corresponding ranking method on the basis of considering variance.

Definition 5. For an HFLE $h_{S}=\left\{s_{\delta_{l}} \mid s_{\delta_{l}} \in S, l=1,2, \ldots, L\right\}[44]$, the score measure is defined as

$$
\rho_{2}\left(h_{S}\right)=\bar{\delta}-\frac{\frac{1}{L} \sum_{l=1}^{L}\left(\delta_{l}-\bar{\delta}\right)^{2}}{\operatorname{var}(g)}
$$

where $\bar{\delta}=\frac{1}{L} \sum_{l=1}^{L} \delta_{l}, \operatorname{var}(g)=\frac{(0-g / 2)^{2}+\cdots+(g-g / 2)^{2}}{g+1}$.

According to the score measure in Definition 5, for two HFLEs $h_{S}^{1}$ and $h_{S^{\prime}}^{2}$ the ranking method is shown as follows:

1. If $\rho_{2}\left(h_{S}^{1}\right)>\rho_{2}\left(h_{S}^{2}\right)$, then $h_{S}^{1}>h_{S}^{2}$;

2. If $\rho_{2}\left(h_{S}^{1}\right)=\rho_{2}\left(h_{S}^{2}\right)$, then $h_{S}^{1} \sim h_{S}^{2}$.

Applying the score measure in Definition 5 to rank the HFLEs in Example 1, the scores of $h_{S^{\prime}}^{1}$ $h_{S}^{2}$ and $h_{S}^{3}$ respectively are

$$
\begin{gathered}
\rho_{2}\left(h_{S}^{1}\right)=2.75 \\
\rho_{2}\left(h_{S}^{2}\right)=3
\end{gathered}
$$




$$
\rho_{2}\left(h_{S}^{3}\right)=2.33
$$

Obviously, the sort result is $h_{S}^{2}>h_{S}^{1}>h_{S^{\prime}}^{3}$ and is the same as Liao and Xu's ranking method [38]. Although both of them consider the mean and variance, the former needs to calculate the score function value and variance value respectively, while the latter only needs to calculate the score function value to get the result. Therefore, the ranking method proposed by Wei and Ren [44] is more simple and effective than Liao and Xu's method [38] by comparison.

Based on the existing method of the hesitant degree [49,50], a ranking method based on the hesitance degree developed by Liao and Qin [47] is as follows.

Definition 6. For an HFLE $h_{S}=\left\{s_{\delta_{l}} \mid s_{\delta_{l}} \in S, l=1,2, \ldots, L\right\}[47]$, the score measure is defined as follows:

$$
\rho_{3}\left(h_{S}\right)=\left(1-\frac{L \ln L}{g \ln g}\right) \times\left(\frac{1}{L} \sum_{l=1}^{L} \frac{\delta_{l}}{g}\right)
$$

Apply the score measure in Definition 6 to rank the HFLEs in Example 1. The scores of $h_{S^{\prime}}^{1} h_{S^{\prime}}^{2}$ and $h_{S}^{3}$ respectively are

$$
\begin{gathered}
\rho_{3}\left(h_{S}^{1}\right)=0.4355 \\
\rho_{3}\left(h_{S}^{2}\right)=0.5 \\
\rho_{3}\left(h_{S}^{3}\right)=0.3467
\end{gathered}
$$

According to the sorting method of Definition 6, the result is $h_{S}^{2}>h_{S}^{1}>h_{S}^{3}$, the same as the former sorting methods. The difference is that Definition 4 and Definition 5 mainly consider the variance of HFLEs, while Definition 6 considers the hesitancy degree of HFLEs. Although the ranking methods of Definition 5 and Definition 6 are more efficient than Definition 4, they will strengthen the roles of variance, hesitation, and other parameters in the score measurement calculation process, leading to the deviation of decision-making results.

\section{Novel Score Measure Related to Hesitant Fuzzy Linguistic Information}

From the above analysis, the existing score measures of HFLEs and their corresponding ranking methods have low operation efficiency or the influence of reinforcement variance and hesitancy degree on decision-making results. A new score measure of HFLEs and their corresponding ranking method is developed, and some properties of the developed score measure are discussed.

Definition 7. Let $h_{S}=\left\{s_{\delta_{l}} \mid s_{\delta_{l}} \in S, l=1,2, \ldots, L\right\}$ be an HFLE and $L$ be the number of linguistic terms in $h_{S}$. The novel score measure $\mathbb{Z}_{\lambda}\left(h_{S}\right)$ of an HFLE is defined as follows:

$$
\mathbb{Z}_{\lambda}\left(h_{S}\right)=\left(\left(\left(\Delta\left(s_{\delta_{1}}\right)\right)^{\lambda}+\left(\Delta\left(s_{\delta_{2}}\right)\right)^{\lambda}+\ldots+\left(\Delta\left(s_{\delta_{L}}\right)\right)^{\lambda}\right) / L\right)^{1 / \lambda}
$$

where the parameter $\lambda(0<\lambda \leq 1)$ is a constant, given by the decision-maker according to the actual decision-making needs.

When $\lambda=1$, the new score measure is $\mathbb{Z}_{\lambda}\left(h_{S}\right)=\left(\Delta\left(s_{\delta_{1}}\right)+\Delta\left(s_{\delta_{2}}\right)+\ldots+\Delta\left(s_{\delta_{L}}\right)\right) / L$, and the new score measure in Definition 7 is equivalent to the score measure in Definition 4.

Next, some properties of the new score measure $\mathbb{Z}_{\lambda}\left(h_{S}\right)$ are discussed.

Theorem 1. Let $h_{S}=\left\{s_{\delta_{l}} \mid s_{\delta_{l}} \in S, l=1,2, \ldots, L\right\}$ be an HFLE and $L$ be the number of linguistic terms in $h_{S}$. The new score measure is $\mathbb{Z}_{\lambda}\left(h_{S}\right) \in[0,1]$. 
Proof. Suppose that $s^{+}=\max \left\{s_{\delta_{l}} l=1,2, \ldots, L\right\}$ and $s^{-}=\min \left\{s_{\delta_{l}} l l=1,2, \ldots, L\right\}$ because $\lambda(0<\lambda \leq 1)$ and $\Delta\left(s_{\delta_{l}}\right) \in[0,1](l=1,2, \ldots, L)$. Therefore,

$$
\begin{gathered}
\mathbb{Z}_{\lambda}\left(h_{S}\right)=\left(\left(\left(\Delta\left(s_{\delta_{1}}\right)\right)^{\lambda}+\left(\Delta\left(s_{\delta_{2}}\right)\right)^{\lambda}+\ldots+\left(\Delta\left(s_{\delta_{L}}\right)\right)^{\lambda}\right) / L\right)^{1 / \lambda} \\
\leq\left(\left(\left(\Delta\left(s^{+}\right)\right)^{\lambda}+\left(\Delta\left(s^{+}\right)\right)^{\lambda}+\ldots+\left(\Delta\left(s^{+}\right)\right)^{\lambda}\right) / L\right)^{1 / \lambda} \\
=\left(\left(L \times\left(\Delta\left(s^{+}\right)\right)^{\lambda}\right) / L\right)^{1 / \lambda}=\Delta\left(s^{+}\right) \leq 1 \\
\mathbb{Z}_{\lambda}\left(h_{S}\right)=\left(\left(\left(\Delta\left(s_{\delta_{1}}\right)\right)^{\lambda}+\left(\Delta\left(s_{\delta_{2}}\right)\right)^{\lambda}+\ldots+\left(\Delta\left(s_{\delta_{L}}\right)\right)^{\lambda}\right) / L\right)^{1 / \lambda} \\
\geq\left(\left(\left(\Delta\left(s^{-}\right)\right)^{\lambda}+\left(\Delta\left(s^{-}\right)\right)^{\lambda}+\ldots+\left(\Delta\left(s^{-}\right)\right)^{\lambda}\right) / L\right)^{1 / \lambda} \\
=\left(\left(L \times\left(\Delta\left(s^{-}\right)\right)^{\lambda}\right) / L\right)^{1 / \lambda}=\Delta\left(s^{-}\right) \geq 0
\end{gathered}
$$

Obviously, $0 \leq \mathbb{Z}_{\lambda}\left(h_{S}\right) \leq 1$.

Theorem 2. For a single valued HFLE $h_{S}=\left\{s_{\delta}\right\}$, its score value is $\mathbb{Z}_{\lambda}\left(h_{S}\right)=\Delta\left(s_{\delta}\right)$. If $h_{S}$ is an empty set, then $\mathbb{Z}_{\lambda}\left(h_{S}\right)=0$; if $h_{S}$ is a full set, then $\mathbb{Z}_{\lambda}\left(h_{S}\right)=1$.

Theorem 3. For two HFLEs $h_{S}^{1}$ and $h_{S^{\prime}}^{2}$ if the order of the elements in $h_{S}^{1}$ and $h_{S}^{2}$ is increasing, and $L_{1}=L_{2}$; if $h_{S}^{1} \leq h_{S}^{2}$, then $\mathbb{Z}_{\lambda}\left(h_{S}^{1}\right) \leq \mathbb{Z}_{\lambda}\left(h_{S}^{2}\right)$.

Proof. Because the two HFLEs $h_{S}^{1}=\left\{s_{\delta_{l}}^{1} l=1,2, \ldots, L_{1}\right\}$ and $h_{S}^{2}=\left\{s_{\delta_{l}}^{2} l=1,2, \ldots, L_{2}\right\}$ have the same length and the order of the elements of them is increasing, namely $L=L_{1}=L_{2}, s_{\delta_{l}}^{1}$ and $s_{\delta_{l}}^{2}$ are the lth linguistic terms of $h_{S}^{1}$ and $h_{S^{\prime}}^{2}$, respectively. Therefore, according to Definition 3 , if $h_{S}^{1} \leq h_{S^{\prime}}^{2}$ then $s_{\delta_{l}}^{1} \leq s_{\delta_{l}}^{2}(l=1,2, \ldots, L)$.

Because $0<\lambda \leq 1$, then $\left(\Delta\left(s_{\delta_{l}}^{1}\right)\right)^{\lambda} \leq \Delta\left(\left(s_{\delta_{l}}^{2}\right)\right)^{\lambda}(l=1,2, \ldots, L)$.

Therefore

$$
\left(\left(\left(\Delta\left(s_{\delta_{1}}^{1}\right)\right)^{\lambda}+\left(\Delta\left(s_{\delta_{2}}^{1}\right)\right)^{\lambda}+\ldots+\left(\Delta\left(s_{\delta_{L}}^{1}\right)\right)^{\lambda}\right) / L\right)^{1 / \lambda} \leq\left(\left(\left(\Delta\left(s_{\delta_{1}}^{2}\right)\right)^{\lambda}+\left(\Delta\left(s_{\delta_{2}}^{2}\right)\right)^{\lambda}+\ldots+\left(\Delta\left(s_{\delta_{L}}^{2}\right)\right)^{\lambda}\right) / L\right)^{1 / \lambda}
$$

Namely

$$
\mathbb{Z}_{\lambda}\left(h_{S}^{1}\right) \leq \mathbb{Z}_{\lambda}\left(h_{S}^{2}\right)
$$

Therefore, if

$$
h_{S}^{1} \leq h_{S}^{2}
$$

Then

$$
\mathbb{Z}_{\lambda}\left(h_{S}^{1}\right) \leq \mathbb{Z}_{\lambda}\left(h_{S}^{2}\right)
$$

The ranking method according to the score measure in Definition 7 is defined as follows:

Definition 8. For two HFLEs $h_{S}^{1}$ and $h_{S}^{2}$, the new ranking method is defined under these terms:

1. If $\mathbb{Z}_{\lambda}\left(h_{S}^{1}\right)>\mathbb{Z}_{\lambda}\left(h_{S}^{2}\right)$, it means $h_{S}^{1}$ is larger than $h_{S^{\prime}}^{2}$ represented as $h_{S}^{1}>\mathbb{Z}_{S^{\prime}}^{2}$

2. If $\mathbb{Z}_{\lambda}\left(h_{S}^{1}\right)=\mathbb{Z}_{\lambda}\left(h_{S}^{2}\right)$, it means $h_{S}^{1}$ is same as $h_{S^{\prime}}^{2}$ represented as $h_{S}^{1} \sim \mathbb{Z}_{S^{\prime}} h^{2}$

3. If $\mathbb{Z}_{\lambda}\left(h_{S}^{1}\right)<\mathbb{Z}_{\lambda}\left(h_{S}^{2}\right)$, it means $h_{S}^{1}$ is smaller than $h_{S}^{2}$, represented as $h_{S}^{1}<{ }_{\mathbb{Z}} h_{S}^{2}$.

In addition, the sorting method is based on the non-arithmetic form, and only needs a one-step calculation to get the sorting result, which is better than the method in Definition 4. 
Suppose that $\lambda=0.1$. According to Definition 7 , the score values of the three HFLEs in Example 1 are

$$
\begin{aligned}
& \mathbb{Z}_{\lambda}\left(h_{S}^{1}\right)=0.4742 \\
& \mathbb{Z}_{\lambda}\left(h_{S}^{2}\right)=0.5000 \\
& \mathbb{Z}_{\lambda}\left(h_{S}^{3}\right)=0.4203
\end{aligned}
$$

where

$$
\mathbb{Z}_{\lambda}\left(h_{S}^{3}\right)<\mathbb{Z}_{\lambda}\left(h_{S}^{1}\right)<\mathbb{Z}_{\lambda}\left(h_{S}^{2}\right)
$$

Thus

$$
h_{S}^{3} \prec_{\mathbb{Z}} h_{S}^{1} \prec_{\mathbb{Z}} h_{S}^{2}
$$

When $\lambda=0.001,0.01,0.1$, the results by the new score measures are shown as Table 1 . The sorting results are $h_{S}^{3} \prec_{\mathbb{Z}} h_{S}^{1} \prec_{\mathbb{Z}} h_{S}^{2}$ in different parameter $\lambda$.

Table 1. Ranking results by novel score measure.

\begin{tabular}{ccccc}
\hline Novel Score Values of HFLEs (Definition 7) & $\boldsymbol{h}_{S}^{1}$ & $\boldsymbol{h}_{S}^{2}$ & $\boldsymbol{h}_{\boldsymbol{S}}^{3}$ & Ranking Results \\
\hline $\mathbb{Z}_{\lambda}\left(h_{S}\right) \lambda=0.001$ & 0.4714 & 0.5000 & 0.4111 & $h_{S}^{3} \prec_{\mathbb{Z}} h_{S}^{1}{ }_{\mathbb{Z}} h_{S}^{2}$ \\
$\lambda=0.01$ & 0.4717 & 0.5000 & 0.4120 & $h_{S}^{3} \prec_{\mathbb{Z}}^{1} h_{S}^{1} h_{S}^{2}$ \\
$\lambda=0.1$ & 0.4742 & 0.5000 & 0.4203 & $h_{S}^{3}{ }_{\mathbb{Z}} h_{S}^{1}{ }_{\mathbb{Z}} h_{S}^{2}$ \\
\hline
\end{tabular}

To compare the advantages and disadvantages between the developed score measure and the previous methods, different score measures and their ranking results are compared in Table 2. According to Table 2, the ranking results of the new developed score measure are consistent with the other three. However, in the MADM process, the actual operation is different. The ranking method in Definition 4 is an arithmetic ranking method based on measure function, which will make the decision process more complex and time-consuming. The ranking methods in Definition 5 and Definition 6 will strengthen the role of variance, hesitation degree, and other parameters in the score measure calculation process, leading to the deviation of decision-making results. Therefore, the developed ranking method (Definition 8) is better than the other three methods, which can help decision makers to make more reasonable decisions.

Table 2. Score measures of different hesitant fuzzy linguistic elements (HFLEs) and their corresponding ranking results.

\begin{tabular}{cc}
\hline Ranking Methods & Ranking Results \\
\hline Definition 4 (Liao and Xu's method [33]) & $h_{S}^{3}<h_{S}^{1}<h_{S}^{2}$ \\
Definition 5 (Wei and Ren's method [39]) & $h_{S}^{3}<h_{S}^{1}<h_{S}^{2}$ \\
Definition 6 (Liao and Qin's method [40]) & $h_{S}^{3}<h_{S}^{1}<h_{S}^{2}$ \\
Definition 7 (Our developed method) & $h_{S}^{3}<{ }_{\mathbb{Z}_{S}}^{1} h_{\mathbb{Z}}^{1} h_{S}^{2}$ \\
\hline
\end{tabular}

\section{Hybrid TODIM Method for Law Enforcement Possibility Evaluation of Judgment Debtors}

\subsection{Problem Description}

The hybrid TODIM method with crisp numbers and HFLTSs is used to evaluate the law enforcement possibility of judgment debtors. To better describe the process, the variables involved in the developed method are defined by symbols as follows:

1. $A=\left\{A_{1}, A_{2}, \ldots, A_{m}\right\}$ is a collection of $m$ judgment debtors, where $A_{i}$ represents the $i$ th judgment debtor, $i=1,2, \ldots, m$. 
2. $C=\left\{C_{1}, C_{2}, \ldots, C_{n}\right\}$ is the set of $n$ attributes of judgment debtors, where $C_{j}$ represents the $j$ th attribute of judgment debtors.

3. $S=\left\{s_{0}, s_{1}, \ldots, s_{g}\right\}$ is the set of linguistic scales used by the law enforcement officers to evaluate the attributes of judgment debtors, where $s_{\varepsilon}$ represents the $\varepsilon$ th linguistic scale, $\varepsilon=0,1, \ldots, g$. In general, the larger the scale of $\varepsilon$, the higher the corresponding evaluation level. For example, the evaluation information of the credibility of the judgment debtor has seven scales; that is, $S=\left\{s_{0}, s_{1}, s_{2}, s_{3}, s_{4}, s_{5}, s_{6}\right\}$ are very poor, relatively poor, poor, medium, good, very good, and very good, respectively.

4. $h_{i j}$ and $h_{S}^{i j}$ are the values of the attribute $C_{j}$ of the judgment debtor $A_{i}$, expressed by crisp numbers and HFLTSs, respectively.

5. $\omega=\left\{\omega_{1}, \omega_{2}, \ldots, \omega_{n}\right\}$ is the attribute weight vector, where $\omega_{j}$ represents the weight or importance of the attributes, satisfying $\omega_{j} \geq 0$ and $\sum_{j=1}^{n} \omega_{j}=1, j=1,2, \ldots, n$. Here, the weight of the attributes can be given by law enforcement officers.

\subsection{Hybrid TODIM Method for Law Enforcement Possibility Evaluation}

In this section, a hybrid TODIM method for evaluating the law enforcement possibility of judgment debtors is developed. In the problem, the values of the attributes of judgment debtors are expressed by crisp numbers and HFLTSs, and the weights are represented by crisp numbers.

In the problem of law enforcement possibility evaluation, it is necessary to determine the reference attribute first. Usually, the attribute with the largest weight value is selected as the reference attribute $C_{r}$, and then the relative weight value $\omega_{j r}$ of the attribute $C_{j}(j=1,2, \ldots, n)$, relative to the reference attribute $C_{r}$, is calculated by Equation (1). According to the comparison rules of crisp numbers and the score measure $\mathbb{Z}_{\lambda}\left(H_{S}\right)$ of HFLTSs, the evaluation values between two judgment debtors under attribute $C_{j}$ are compared. The gain value and loss value of judgment debtor $A_{i}$ over $A_{k}$ under attribute $C_{j}$ are calculated according to Equation (10) or (11):

1. If $j=1,2, \ldots, j_{1}$, then the value $R=r_{i j}\left(i=1,2, \ldots, m ; j=1,2, \ldots, j_{1}\right)$ of attribute $C_{j}$ of judgment debtor $A_{i}$ can be expressed by crisp numbers, namely $r_{i j}=h_{i j}$. The gains and losses function of judgment debtor $A_{i}$ over $A_{k}$ under attribute $C_{j}\left(j=1,2, \ldots, j_{1}\right)$ is as follows:

$$
\phi_{j}\left(A_{i}, A_{k}\right)=\left\{\begin{array}{ccc}
\sqrt{\omega_{j r}\left(h_{i j}-h_{k j}\right) / \sum_{j=1}^{n} \omega_{j r},} & \text { if } & h_{i j}-h_{k j}>0 \\
0, & \text { if } & h_{i j}-h_{k j}=0 \\
-\frac{1}{\theta} \sqrt{\sum_{j=1}^{n} \omega_{j r}\left(h_{k j}-h_{i j}\right) / \omega_{j r},} & \text { if } & h_{i j}-h_{k j}<0
\end{array}\right.
$$

where parameter $\theta$ represents the loss avoidance index of the judgment debtor in the evaluation process and $d\left(h_{i j}, h_{k j}\right)$ is the European distance between $h_{i j}$ and $h_{k j}$.

It is noted that Equation (10) has the following three situations:

1. If $h_{i j}-h_{k j}>0$, then $\phi_{j}\left(A_{i}, A_{k}\right)$ represents a gain;

2. If $h_{i j}-h_{k j}=0$, then $\phi_{j}\left(A_{i}, A_{k}\right)$ represents nil;

3. If $h_{i j}-h_{k j}<0$, then $\phi_{j}\left(A_{i}, A_{k}\right)$ represents a loss. 
2. If $j=j_{1}+1, j_{1}+2, \ldots, n$, then the value $R=r_{i j}\left(i=1,2, \ldots, m ; j=j_{1}+1, j_{1}+2, \ldots, n\right)$ of attribute $C_{j}$ of judgment debtor $A_{i}$ can be expressed by HFLTSs, namely $r_{i j}=h_{S}^{i j}$. The gains and losses function of judgment debtor $A_{i}$ over $A_{k}$ under attribute $C_{j}\left(j=j_{1}+1, j_{1}+2, \ldots, n\right)$ is as follows:

$$
\phi_{j}\left(A_{i}, A_{k}\right)=\left\{\begin{array}{cll}
\sqrt{\omega_{j r} d\left(h_{S}^{i j}, h_{S}^{k j}\right) / \sum_{j=1}^{n} \omega_{j r},} & \text { if } & \mathbb{Z}_{\lambda}\left(h_{S}^{i j}\right)-\mathbb{Z}_{\lambda}\left(h_{S}^{k j}\right)>0 \\
0 & \text { if } & \mathbb{Z}_{\lambda}\left(h_{S}^{i j}\right)-\mathbb{Z}_{\lambda}\left(h_{S}^{k j}\right)=0 \\
-\frac{1}{\theta} \sqrt{\sum_{j=1}^{n} \omega_{j r} d\left(h_{S}^{k j}, h_{S}^{i j}\right) / \omega_{j r},} & \text { if } & \mathbb{Z}_{\lambda}\left(h_{S}^{i j}\right)-\mathbb{Z}_{\lambda}\left(h_{S}^{k j}\right)<0
\end{array}\right.
$$

where parameter $\theta$ represents the loss avoidance index of the judgment debtor in the evaluation process and $d\left(h_{S}^{i j}, h_{S}^{k j}\right)$ is the European distance between $h_{S}^{i j}$ and $h_{S}^{k j}$ [42], expressed as

$$
d\left(h_{S}^{i j}, h_{S}^{k j}\right)=\sqrt{\frac{1}{\# h_{S}} \sum_{l=1}^{\# h_{S}}\left(\Delta^{-1}\left(s_{\delta_{l}}^{i j}\right)-\Delta^{-1}\left(s_{\delta_{l}}{ }^{k j}\right)\right)^{2}}
$$

It is noted that Equation (11) has the following three situations:

1. If $\mathbb{Z}_{\lambda}\left(h_{S}^{i j}\right)-\mathbb{Z}_{\lambda}\left(h_{S}^{k j}\right)>0$, then $\phi_{j}\left(A_{i}, A_{k}\right)$ represents a gain;

2. If $\mathbb{Z}_{\lambda}\left(h_{S}^{i j}\right)-\mathbb{Z}_{\lambda}\left(h_{S}^{k j}\right)=0$, then $\phi_{j}\left(A_{i}, A_{k}\right)$ represents nil;

3. If $\mathbb{Z}_{\lambda}\left(h_{S}^{i j}\right)-\mathbb{Z}_{\lambda}\left(h_{S}^{k j}\right)<0$, then $\phi_{j}\left(A_{i}, A_{k}\right)$ represents a loss.

Then, the gains and losses of the attribute $C_{j}(j=1,2, \ldots, n)$ of judgment debtor $A_{i}$ are aggregated over judgment debtor $A_{k}$ to obtain the dominance degree $\delta\left(A_{i}, A_{k}\right)$ :

$$
\delta\left(A_{i}, A_{k}\right)=\sum_{j=1}^{n} \phi_{j}\left(A_{i}, A_{k}\right), i, k=1,2, \ldots, m
$$

Finally, the overall prospect value $\pi\left(A_{i}\right)$ of judgment debtor $A_{i}(i=1,2, \ldots, m)$ is calculated by Equation (14):

$$
\pi\left(A_{i}\right)=\frac{\sum_{k=1}^{m} \delta\left(A_{i}, A_{k}\right)-\min _{i}\left\{\sum_{k=1}^{m} \delta\left(A_{i}, A_{k}\right)\right\}}{\max _{i}\left\{\sum_{k=1}^{m} \delta\left(A_{i}, A_{k}\right)\right\}-\min _{i}\left\{\sum_{k=1}^{m} \delta\left(A_{i}, A_{k}\right)\right\}}, i=1,2, \ldots, m
$$

Obviously, $0 \leq \pi\left(A_{i}\right) \leq 1$. The larger the overall prospect value $\pi\left(A_{i}\right)$ of judgment debtor $A_{i}(i=1,2, \ldots, m)$, the more likely the judgment debtor $A_{i}(i=1,2, \ldots, m)$ is to implement the legal document. Therefore, according to the overall prospect value $\pi\left(A_{i}\right)$ of judgment debtor $A_{i}(i=1,2, \ldots, m)$, the relative law enforcement possibility of judgment debtors is calculated to judge who is more likely to implement the legal document.

According to the above discussion and analysis, the steps of the hybrid TODIM method for law enforcement possibility evaluation of judgment debtors can be summarized as follows:

1. Give the evaluation values of judgment debtor $A_{i}$ under each attribute $C_{j}$, and establish the evaluation matrix $R=\left(r_{i j}\right)_{m \times n}$. If the evaluation value of the attribute $C_{j}\left(j=1,2, \ldots, j_{1}\right)$ is a crisp number, it is expressed as $r_{i j}=h_{i j}$; if the evaluation value of the attribute $C_{j}\left(j=1,2, \ldots, j_{1}\right)$ is an HFLTS, it is represented as $r_{i j}=H_{S}^{i j}$.

2. Construct the advantage-disadvantage matrix between two judgment debtors under different attributes. In the matrix, $\mathrm{A}$ or $\mathrm{D}$ means that $A_{i}$ is better or smaller than $A_{k}$. 
3. Standardize the evaluation matrix, which mainly refers to transforming the attribute value $r_{i j}$ expressed by an HFLTS into the standard form, according to Definition 2.

4. Regard the attribute with the maximum weight value as the reference attribute $C_{r}$. Then, calculate the relative weight value $\omega_{j r}$ of each attribute $C_{j}$ over the reference attribute $C_{r}$.

5. Calculate the gains and losses $\phi_{j}\left(A_{i}, A_{k}\right)$ of judgment debtor $A_{i}(i=1,2, \ldots, m)$ over judgment debtor $A_{k}(k=1,2, \ldots, m)$ under the attribute $C_{j}(j=1,2, \ldots, n)$ by Equation (10) or Equation (11).

6. Calculate the dominance degree $\delta\left(A_{i}, A_{k}\right)$ of judgment debtor $A_{i}(i=1,2, \ldots, m)$ over judgment debtor $A_{k}(k=1,2, \ldots, m)$ by Equation (13).

7. Calculate the overall prospect value $\pi\left(A_{i}\right)$ of judgment debtor $A_{i}(i=1,2, \ldots, m)$ by Equation (14).

8. Rank the judgment debtor $A_{i}(i=1,2, \ldots, m)$ according to the overall prospect value $\pi\left(A_{i}\right)$. The larger the overall prospect value $\pi\left(A_{i}\right)$ of judgment debtor $A_{i}(i=1,2, \ldots, m)$, the more likely the judgment debtor $A_{i}(i=1,2, \ldots, m)$ is to implement the legal document.

\section{Illustration Examples}

\subsection{Evaluation Steps}

In this section, an example is used to explain the process of the hybrid TODIM method for law enforcement possibility evaluation of judgment debtors. There were four judgment debtors $\left(A_{1}-A_{4}\right)$. Four attributes were selected to evaluate the law enforcement possibility of judgment debtors by experts, which were the following: (annual income - annual expenditure)/execution target amount $\left(C_{1}\right)$, frozen property/target amount $\left(C_{2}\right)$, recent abnormal transaction amount/(daily transaction amount $x$ target amount) $\left(C_{3}\right)$, and credibility $\left(C_{4}\right)$. The weight vector is $W=(0.2,0.25,0.25,0.3)^{T}$. The former three attributes could be obtained by calculation and expressed by crisp numbers, and the last attribute, credibility, was expressed by HFLTSs and given by the law enforcement officers' experience. The evaluation steps of the law enforcement possibility of judgment debtors are as follows.

First, give the evaluation values of the judgment debtor $A_{i}$ under each attribute $C_{j}$, and establish the evaluation matrix $R=\left(r_{i j}\right)_{m \times n}$. The evaluation matrix is shown in Table 3 .

Table 3. Law enforcement possibility evaluation matrix of judgment debtors.

\begin{tabular}{ccccc}
\hline & $C_{1}$ & $C_{2}$ & $C_{3}$ & $C_{4}$ \\
\hline$A_{1}$ & 0.05 & 0.01 & 0.16 & $\left\{s_{1}, s_{2}, s_{3}\right\}$ \\
$A_{2}$ & 0.09 & 0.10 & 0.05 & $\left\{s_{4}\right\}$ \\
$A_{3}$ & 0.01 & 0.12 & 0.14 & $\left\{s_{3}, s_{4}\right\}$ \\
$A_{4}$ & 0.08 & 0.06 & 0.03 & $\left\{s_{2}, s_{3}, s_{4}\right\}$ \\
\hline
\end{tabular}

Next, construct the advantage-disadvantage matrix between two judgment debtors under different attributes. The matrix is shown in Table 4. For example, under the attribute $C_{1}$, judgment debtor $A_{1}$ is smaller than $A_{2}$, which is expressed as $\mathrm{D}$.

Table 4. Advantage-disadvantage matrix under each attribute $C_{j}$ between two judgment debtors.

\begin{tabular}{ccccccc}
\hline & $A_{1} / A_{2}$ & $A_{1} / A_{3}$ & $A_{1} / A_{4}$ & $A_{2} / A_{3}$ & $A_{2} / A_{4}$ & $A_{3} / A_{4}$ \\
\hline$C_{1}$ & $\mathrm{D}$ & $\mathrm{A}$ & $\mathrm{D}$ & $\mathrm{A}$ & $\mathrm{A}$ & $\mathrm{D}$ \\
$C_{2}$ & $\mathrm{D}$ & $\mathrm{D}$ & $\mathrm{D}$ & $\mathrm{D}$ & $\mathrm{A}$ & $\mathrm{A}$ \\
$C_{3}$ & $\mathrm{~A}$ & $\mathrm{~A}$ & $\mathrm{~A}$ & $\mathrm{D}$ & $\mathrm{A}$ & $\mathrm{A}$ \\
$C_{4}$ & $\mathrm{D}$ & $\mathrm{D}$ & $\mathrm{D}$ & $\mathrm{A}$ & $\mathrm{A}$ & $\mathrm{A}$ \\
\hline
\end{tabular}

Standardize the evaluation matrix. The normalized evaluation matrix is shown in Table 5. 
Table 5. Normalized law enforcement possibility evaluation matrix of judgment debtors.

\begin{tabular}{ccccc}
\hline & $C_{1}$ & $C_{2}$ & $C_{3}$ & $C_{4}$ \\
\hline$A_{1}$ & 0.05 & 0.01 & 0.16 & $\left\{s_{1}, s_{2}, s_{3}\right\}$ \\
$A_{2}$ & 0.09 & 0.10 & 0.05 & $\left\{s_{4}, s_{4}, s_{4}\right\}$ \\
$A_{3}$ & 0.01 & 0.12 & 0.14 & $\left\{s_{3}, s_{4}, s_{4}\right\}$ \\
$A_{4}$ & 0.08 & 0.06 & 0.03 & $\left\{s_{2}, s_{3}, s_{4}\right\}$ \\
\hline
\end{tabular}

Following that, regard the attribute with the maximum weight value as the reference attribute $C_{r}$, and calculate the relative weight value $\omega_{j r}$ of each attribute $C_{j}$ over the reference attribute $C_{r}$. As a key factor in the evaluation of law enforcement possibility, the credibility of judgment debtors $\left(C_{4}\right)$ is more appropriate to be the reference attribute; that is $C_{r}=C_{4}$, with its corresponding weight $\omega_{r}=\omega_{4}=0.3$. The relative weight of each attribute $C_{j}$ is shown in Table 6.

Table 6. The relative weight of each attribute $C_{j}$.

\begin{tabular}{ccccc}
\hline & $C_{1}$ & $C_{2}$ & $C_{3}$ & $C_{4}$ \\
\hline$w j$ & 0.2 & 0.25 & 0.25 & 0.3 \\
$w j r$ & 0.67 & 0.83 & 0.83 & 1 \\
\hline
\end{tabular}

Calculate the gains and losses $\phi_{j}\left(A_{i}, A_{k}\right)$ of judgment debtor $A_{i}(i=1,2, \ldots, m)$ over judgment debtor $A_{k}(k=1,2, \ldots, m)$ under the attribute $C_{j}(j=1,2, \ldots, n)$ by Equation (10) or Equation (11). Meanwhile, according to [17], generally, assume that $\theta=1$. The calculation results are shown in Table 7 .

Table 7. Gains and losses of judgment debtor $A_{i}$ over judgment debtor $A_{k}$ under different attributes $C_{j}$.

\begin{tabular}{ccccccccc}
\hline & \multicolumn{9}{c}{$C_{1}$} \\
\cline { 2 - 9 } & $A_{1}$ & $A_{2}$ & $A_{3}$ & $A_{4}$ & $A_{1}$ & $A_{2}$ & $A_{3}$ & $A_{4}$ \\
\hline$A_{1}$ & 0 & -0.4472 & 0.0894 & -0.3873 & 0 & -0.6000 & -0.6633 & -0.4472 \\
$A_{2}$ & 0.0894 & 0 & 0.1265 & 0.0447 & 0.1500 & 0 & -0.2828 & 0.1000 \\
$A_{3}$ & -0.4472 & -0.6325 & 0 & -0.5916 & 0.1658 & 0.0707 & 0 & 0.1225 \\
$A_{4}$ & 0.0775 & -0.2236 & 0.1183 & 0 & 0.1118 & -0.4000 & -0.4899 & 0 \\
\hline & \multicolumn{1}{c}{$C_{3}$} & & & & & $C_{4}$ & & $A_{4}$ \\
\hline & $A_{1}$ & $A_{2}$ & $A_{3}$ & $A_{4}$ & $A_{1}$ & $A_{2}$ & $A_{3}$ & -0.7454 \\
$A_{1}$ & 0 & 0.1658 & 0.0707 & 0.1803 & 0 & -1.0955 & -0.9809 & 0.2541 \\
$A_{2}$ & -0.6633 & 0 & -0.6000 & 0.0707 & 0.3287 & 0 & 0.1699 & 0.2021 \\
$A_{3}$ & -0.2828 & 0.1500 & 0 & 0.1658 & 0.2943 & -0.5663 & 0 & 0 \\
$A_{4}$ & -0.7211 & -0.2828 & -0.6633 & 0 & 0.2236 & -0.8469 & -0.6735 & 0 \\
\hline
\end{tabular}

Calculate the dominance degree $\delta\left(A_{i}, A_{k}\right)$ of judgment debtor $A_{i}(i=1,2, \ldots, m)$ over judgment debtor $A_{k}(k=1,2, \ldots, m)$ by Equation (13). The dominance degree of judgment debtor $A_{i}$ over judgment debtor $A_{k}$ is shown in Table 8.

Table 8. Dominance degree of judgment debtor $A_{i}$ over judgment debtor $A_{k}$.

\begin{tabular}{ccccc}
\hline & $A_{1}$ & $A_{2}$ & $A_{3}$ & $A_{4}$ \\
\hline$A_{1}$ & 0 & -1.9769 & -1.4841 & -1.3996 \\
$A_{2}$ & -0.0952 & 0 & -0.5864 & 0.4695 \\
$A_{3}$ & -0.2699 & -0.9781 & 0 & -0.1013 \\
$A_{4}$ & -0.3082 & -1.7533 & -1.7084 & 0 \\
\hline
\end{tabular}


Next, calculate the overall prospect value $\pi\left(A_{i}\right)$ of judgment debtor $A_{i}(i=1,2, \ldots, m)$ by Equation (14). The overall prospect values are $\pi\left(A_{1}\right)=0, \pi\left(A_{2}\right)=1, \pi\left(A_{3}\right)=0.7554$, and $\pi\left(A_{4}\right)=0.2346$, respectively.

Step 8: rank the judgment debtor $A_{i}(i=1,2, \ldots, m)$ according to the overall prospect value $\pi\left(A_{i}\right)$, the sort result is $\pi\left(A_{2}\right)>\pi\left(A_{3}\right)>\pi\left(A_{4}\right)>\pi\left(A_{1}\right)$.

The judgment debtor $A_{2}$ has the largest overall prospect value $\pi\left(A_{i}\right)$. Therefore, $A_{2}$ is most likely to implement the legal document, followed by the judgment debtors $A_{3}$ and $A_{4}$. The least likely of the group is judgment debtor $A_{1}$.

\subsection{Sensitivity Analysis}

The law enforcement possibility evaluation of judgment debtors based on the hybrid TODIM method involves the attenuation coefficient $\theta$ and the parameter $\lambda$ in the score measure of HFLTSs. Sensitivity analysis is mainly used to analyze the influence of different parameter values on the evaluation results by constantly changing the value of the parameters $\theta$ and $\lambda$.

First of all, the sensitivity of the attenuation coefficient $\theta$ was analyzed. The evaluation results of the law enforcement possibility under different attenuation coefficients $\theta$ are shown in Table 9 for when the attenuation coefficient $\theta=1,2,3,4$. The results show that there was no change in the evaluation results under different attenuation coefficients $\theta$, and the judgment debtor $A_{2}$ always had the largest law enforcement possibility and was most likely to execute the legal documents. In other words, the evaluation results were not sensitive to the value of the attenuation coefficient $\theta$.

Table 9. The evaluation results affected by different $\theta$ attenuation coefficients.

\begin{tabular}{ll}
\hline $\boldsymbol{\theta}$ & Ranking Results \\
\hline 1 & $A_{2}>A_{3}>A_{4}>A_{1}$ \\
2 & $A_{2}>A_{3}>A_{4}>A_{1}$ \\
3 & $A_{2}>A_{3}>A_{4}>A_{1}$ \\
4 & $A_{2}>A_{3}>A_{4}>A_{1}$ \\
\hline
\end{tabular}

Secondly, the sensitivity of the parameter $\lambda$ was analyzed. Because the new score measure of HFLEs needs to be used to determine the relative gain and loss of the judgment debtor, the parameter $\lambda$ acts as an essential role in the score measure. The evaluation results under different parameters $\lambda$ are shown in Table 10 for when $\lambda=0.001,0.01,0.1$. The results show that there was no change in the evaluation results under different parameters. Namely, the evaluation results were not sensitive to the values of the parameter $\lambda$.

Table 10. The evaluation results affected by different $\lambda$ parameters.

\begin{tabular}{cl}
\hline$\lambda$ & Ranking Results \\
\hline 0.001 & $A_{2}>A_{3}>A_{4}>A_{1}$ \\
0.01 & $A_{2}>A_{3}>A_{4}>A_{1}$ \\
0.1 & $A_{2}>A_{3}>A_{4}>A_{1}$ \\
\hline
\end{tabular}

\subsection{Comparative Analysis}

To illustrate the advantages of the hybrid TODIM method, a comparative analysis was made between the hybrid TODIM method and the hybrid TOPSIS method. The steps of the hybrid TOPSIS method are detailed below.

First, ensure the positive ideal solution (PIS) $A^{+}$and the negative ideal solution (NIS) $A^{-}$are as follows. If $j=1,2, \ldots, j_{1}$, then the value of attribute $C_{j}$ of judgment debtor $A_{i}$ is expressed by crisp numbers, namely $r_{i j}=h_{i j}$. The PIS and NIS are

$$
A^{+}=\left\{h_{j}, \max _{i=1}^{m}\left\langle h_{i j}\right\rangle ; j=1,2, \ldots, j_{1}\right\}
$$




$$
A^{-}=\left\{h_{j}, \min _{i=1}^{m}\left\langle h_{i j}\right\rangle ; j=1,2, \ldots, j_{1}\right\}
$$

If $j=j_{1}+1, j_{1}+2, \ldots, n$, then the value of attribute $C_{j}$ of judgment debtor $A_{i}$ is expressed by HFLTSs, namely $r_{i j}=h_{S}^{i j}$. The PIS and NIS are

$$
\begin{aligned}
& A^{+}=\left\{h_{S^{\prime}}^{j} \max _{i=1}^{m}\left\langle s_{\delta_{l}}^{i j}\right\rangle \mid l=1,2, \ldots, \# h_{S}^{i j} ; j=j_{1}+1, j_{1}+2, \ldots, n\right\} \\
& A^{-}=\left\{h_{S^{\prime}}^{j} \min _{i=1}^{m}\left\langle s_{\delta_{l}}^{i j}\right\rangle \mid l=1,2, \ldots, \# h_{S}^{i j} ; j=j_{1}+1, j_{1}+2, \ldots, n\right\}
\end{aligned}
$$

where $s_{\delta_{l}}^{i j}$ is the $l^{\text {th }}$ linguistic term in $h_{S}^{i j}$.

Based on the evaluation matrix in Table 5, the PIS and NIS are determined by Equations (15)-(18). The results are listed in Table 11.

Table 11. The PIS and NIS of judgment debtors.

\begin{tabular}{ccc}
\hline & $A^{+}$ & $A^{-}$ \\
\hline$C_{1}$ & 0.09 & 0.01 \\
$C_{2}$ & 0.12 & 0.01 \\
$C_{3}$ & 0.16 & 0.03 \\
$C_{4}$ & $\left\{s_{4}, s_{4}, s_{4}\right\}$ & $\left\{s_{1}, s_{2}, s_{3}\right\}$ \\
\hline
\end{tabular}

Second, calculate the Euclidean distance between the judgment debtor $A_{i}$ and the PIS $A^{+}$and the NIS $A^{-}$when the attribute values are crisp numbers and HFLTSs, respectively. If $j=1,2, \ldots, j_{1}$, the Euclidean distance between the judgment debtor $A_{i}$ and the PIS $A^{+}$and the NIS $A^{-}$is as follows:

$$
\begin{aligned}
& d_{i j}^{+}=d_{E}\left(h_{i j}, h_{j+}\right) \\
& d_{i j}^{-}=d_{E}\left(h_{i j}, h_{j-}\right)
\end{aligned}
$$

If $j=j_{1}+1, j_{1}+2, \ldots, n$, the Euclidean distance between the judgment debtor $A_{i}$ and the PIS $A^{+}$ and the NIS $A^{-}$is as follows:

$$
\begin{aligned}
& D_{i j}^{+}=d_{E}\left(h_{S}^{i j}, h_{S}^{j+}\right)=\sqrt{\frac{1}{\# h_{S}} \sum_{l=1}^{\# h_{S}}\left(\Delta^{-1}\left(s_{\delta_{l}}^{i j}\right)-\Delta^{-1}\left(s_{\delta_{l}}^{j}+\right)\right)^{2}} \\
& D_{i j}^{-}=d_{E}\left(h_{S^{i j}}^{i j} h_{S}^{j-}\right)=\sqrt{\frac{1}{\# h_{S}} \sum_{l=1}^{\# h_{S}}\left(\Delta^{-1}\left(s_{\delta_{l}}^{i j}\right)-\Delta^{-1}\left(s_{\delta_{l}}^{j}-\right)\right)^{2}}
\end{aligned}
$$

Therefore, the weighted distance between the judgment debtor $A_{i}$ and the PIS $A^{+}$and the NIS $A^{-}$ respectively are defined as

$$
\begin{aligned}
D_{i}^{+} & =\sum_{j=1}^{j_{1}} \omega_{j} d_{i j}^{+}+\sum_{j=j_{1}+1}^{n} \omega_{j} D_{i j}^{+}, i=1,2, \ldots, m \\
D_{i}^{-} & =\sum_{j=1}^{j_{1}} \omega_{j} d_{i j}^{-}+\sum_{j=j_{1}+1}^{n} \omega_{j} D_{i j^{\prime}}^{-} i=1,2, \ldots, m
\end{aligned}
$$


Furthermore, the closeness index $C I_{i}(i=1,2, \ldots, m)$ of the judgment debtor $A_{i}$ over the PIS $A^{+}$is defined as

$$
C I_{i}=\frac{D_{i}^{-}}{D_{i}^{+}+D_{i}^{-}}, i=1,2, \ldots, m
$$

For the law enforcement possibility evaluation of judgment debtors, calculate the weighted distance $D_{i}^{+}$and $D_{i}^{-}$between the judgment debtor $A_{i}$ and the PIS $A^{+}$and the NIS $A^{-}$. Then, calculate the closeness index $C I_{i}$ of the judgment debtor $A_{i}$ over the PIS $A^{+}$, and obtain the law enforcement possibility evaluation results of the judgment debtors based on the closeness index $C I_{i}$ by Equations (19)-(25). The evaluation result by the hybrid TOPSIS method is shown in Table 12. From Table 12, it is easy to see that the order of the four judgment debtors' law enforcement possibility evaluations is $A_{3}>A_{2}>A_{4}>A_{1}$. Therefore, the law enforcement possibility of judgment debtor $A_{3}$ is the largest, followed by $A_{2}$. Namely, the judgment debtor $A_{3}$ is most likely to implement the legal document in the four judgment debtors.

Table 12. The evaluation results based on the relative closeness index.

\begin{tabular}{ccccc}
\hline & $\boldsymbol{D}_{\boldsymbol{i}}^{+}$ & $\boldsymbol{D}_{\boldsymbol{i}}^{-}$ & $\boldsymbol{C I}_{\boldsymbol{i}}$ & Ranking Result \\
\hline$A_{1}$ & 0.1235 & 0.0515 & 0.2943 & 4 \\
$A_{2}$ & 0.0435 & 0.1315 & 0.7514 & 2 \\
$A_{3}$ & 0.0431 & 0.1382 & 0.7624 & 1 \\
$A_{4}$ & 0.1158 & 0.0647 & 0.3583 & 3 \\
\hline
\end{tabular}

To compare the evaluation results of the hybrid TODIM method and the hybrid TOPSIS method on the law enforcement possibility evaluation of judgment debtors, the evaluation results of the two methods are shown in Figure 2. It can be seen that the performance evaluation results of the hybrid TODIM method are different from those of the hybrid TOPSIS method. The largest law enforcement possibility obtained by the hybrid TODIM method was $A_{2}$, while that of the hybrid TOPSIS method was $A_{3}$. The main reason for the different results is that the hybrid TODIM method fully considers the psychological and behavioral factors of law enforcement officers in the evaluation process of law enforcement possibility, and the evaluation results are more in line with the actual situation. Meanwhile, the hybrid TOPSIS method is based on the assumption that law enforcement officers have complete rationality in the evaluation of the judgment debtors and fails to fully consider the law enforcement officers' psychological and behavioral factors. Therefore, the hybrid TODIM method is more reasonable, accurate, and reliable than the hybrid TOPSIS method.

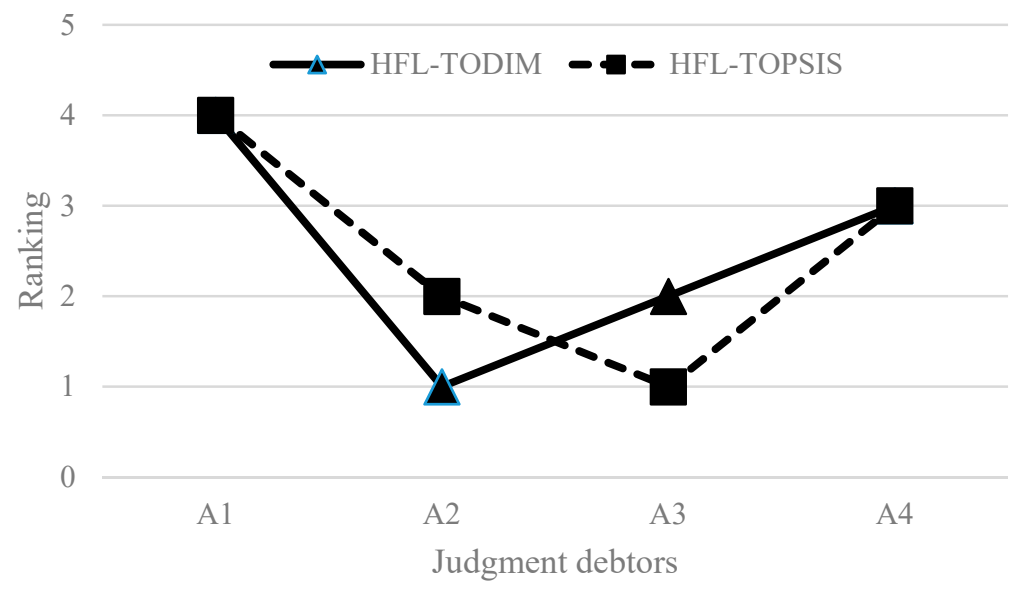

Figure 2. Evaluation results by two different methods. 


\section{Conclusions and Future Works}

In China, the problem of evaluating the law enforcement possibility of judgment debtors has some characteristics. First, at present, there is no quantitative, systematic, and accurate method to assess the law enforcement possibility of judgment debtors. Second, the problem of law enforcement possibility evaluation involves multiple attributes, and the evaluation information in most MADM methods is based on the assumption that the law enforcement officers are completely rational, and they do not consider the influence of the psychological behavior of the judgment debtors. Third, the attribute values of the judgment debtors are represented by crisp numbers and HFLTSs, and the previous TODIM method only considers one form of data. Therefore, a hybrid TODIM method for evaluating the law enforcement possibility of judgment debtors is proposed. The conclusions of the paper are as follows.

Firstly, the developed hybrid TODIM framework for evaluating the possibility of law enforcement of judgment debtors provides a useful tool to judge which judgment debtor is more likely to complement the legal document. The evaluation result is consistent with the actual judicial enforcement practice.

Secondly, the values of the attributes in the evaluation include crisp numbers and HFLTSs. The developed hybrid TODIM method involves two types of data and is different from the previous TODIM method.

Thirdly, the score measure of HFLEs acts as an essential role in describing some attributes of the judgment debtors, such as credibility. Thus, a new score measure for HFLEs is put forward to measure some attributes under the hesitant fuzzy linguistic environment, and some properties are discussed. Additionally, the proposed score measure has the characteristics of simple calculation and high efficiency, and it is superior to the existing score measures in expression of the original evaluation information.

Fourthly, the comparison result shows that the hybrid TODIM method fully considers the psychological and behavioral factors of the law enforcement officers in the evaluation process, and the evaluation result is more in line with the law enforcement officers' experience in the process of handling execution cases. Thus, compared with the hybrid TOPSIS method, the hybrid TODIM method is more suitable for solving the problem.

However, there are some limitations in the paper. Firstly, the attributes are selected by experts, which is subjective and cannot reflect all the attributes of the problem. Therefore, we will collect more data and use the machine learning method to select features and analyze the law enforcement possibility of the judgment debtor. Secondly, the developed hybrid TODIM method is suitable for application to other areas, such as quality management and risk assessment.

Author Contributions: Conceptualization, Z.Z.; methodology, Z.Z. and S.W.; validation, Z.Z.; formal analysis, Z.Z.; investigation, Z.Z. and S.W.; writing—original draft preparation, Z.Z.; writing—review and editing, Z.Z., H.Z. and D.J.; supervision, J.L.; funding acquisition, J.L. and H.Z. All authors have read and agreed to the published version of the manuscript.

Funding: This work is funded by the National Natural Science Foundation of China (No.71672128), National Key Research and Development Program of China (2018YFC0830400), and the Major Project of the 13th Five-year Plan for Education Science in Shandong Province (ZZ2019066).

Acknowledgments: This work is supported by the National Natural Science Foundation of China (No. 71672128), National Key Research and Development Program of China (2018YFC0830400), and the Major Project of the 13th Five-year Plan for Education Science in Shandong Province (ZZ2019066).

Conflicts of Interest: We declare that there is no conflict of interest.

\section{References}

1. Qin, Y.; Zhang, Z.; Liu, X.; Li, M.; Kou, L. Dynamic risk assessment of metro station with interval type-2 fuzzy set and TOPSIS method. J. Intell. Fuzzy Syst. 2015, 29, 93-106. [CrossRef]

2. Srinivasan, V.; Shocker, A.D. Linear programming techniques for multidimensional analysis of preferences. Psychometrika 1973, 38, 337-369. [CrossRef] 
3. Roy, B. Classement et choix en présence de points de vue multiples. Rev. Fr. Inform. Rech. Opér. 1968, 2, 57-75. [CrossRef]

4. Roy, B. Multicriteria Methodology for Decision Aiding; Springer Science \& Business Media: Berlin/Heidelberg, Germany, 2013.

5. Samanta, S.; Sarkar, B. Isomorphism on generalized fuzzy graphs and image visualizations. Soft Comput. 2020. [CrossRef]

6. Samanta, S.; Sarkar, B. A study on generalized fuzzy graphs. J. Intell. Fuzzy Syst. 2018, 35, 3405-3412. [CrossRef]

7. Zhang, W.; Ju, Y.; Liu, X.; Giannakis, M. A mathematical programming-based method for heterogeneous multicriteria group decision analysis with aspirations and incomplete preference information. Comput. Ind. Eng. 2017, 113, 541-557. [CrossRef]

8. Zhang, W.; Ju, Y.; Liu, X. Interval-valued intuitionistic fuzzy programming technique for multicriteria group decision making based on Shapley values and incomplete preference information. Soft Comput. 2017, 21, 5787-5804. [CrossRef]

9. Xu, Z.; Zhao, N. Information fusion for intuitionistic fuzzy decision making: An overview. Inf. Fusion 2016, 28, 10-23. [CrossRef]

10. Zhang, X.; Xu, Z. The TODIM analysis approach based on novel measured functions under hesitant fuzzy environment. Knowl. Based Syst. 2014, 61, 48-58. [CrossRef]

11. Harsanyi, J.C. Cardinal welfare, individualistic ethics, and interpersonal comparisons of utility. J. Political Econ. 1955, 63, 309-321. [CrossRef]

12. Yager, R.R. On ordered weighted averaging aggregation operators in multicriteria decision-making. IEEE Trans. Syst. Manand Cybern. 1988, 18, 183-190. [CrossRef]

13. Yager, R.; Janusz, K.; Gleb, B. Recent Developments in the Ordered Weighted Averaging Operators: Theory and Practice; Springer: Berlin/Heidelberg, Germany, 2011.

14. Xu, Z.S.; Da, Q.L. The ordered weighted geometric averaging operators. Int. J. Intell. Syst. 2002, 17, 709-716. [CrossRef]

15. Mareschal, B.; Brans, J.P.; Vincke, P. Promethee: A New Family of Outranking Methods in Multicriteria Analysis; ULB-Universite Libre de Bruxelles: Bruxelles, Belgium, 1984.

16. Paelinck, J.H.P. Qualitative Multiple Criteria Analysis, Environmental Protection and Multiregional Development; Papers of the Regional Science Association; Springer: Berlin/Heidelberg, Germany, 1976; Volume 36, pp. 59-74.

17. Paelinck, J. Qualitative multicriteria analysis: An application to airport location. Environ. Plan. A 1977, 9 , 883-895. [CrossRef]

18. Paelinck, J.H.P. Qualiflex: A flexible multiple-criteria method. Econ. Lett. 1978, 1, 193-197. [CrossRef]

19. Opricovic, S. Multicriteria optimization of civil engineering systems. Fac. Civ. Eng. Belgrade 1998, 2, 5-21.

20. Gomes, L.; Lima, M. TODIM: Basics and application to multicriteria ranking of projects with environmental impacts. Found. Comput. Decis. Sci. 1992, 16, 113-127.

21. Gomes, L.; Lima, M. From modeling individual preferences to multicriteria ranking of discrete alternatives: A look at prospect theory and the additive difference model. Found. Comput. Decis. Sci. 1992, 17, 171-184.

22. Gomes, L.F.A.M.; Rangel, L.A.D.; Maranhão, F.J.C. Multicriteria analysis of natural gas destination in Brazil: An application of the TODIM method. Math. Comput. Model. 2009, 50, 92-100. [CrossRef]

23. Gomes, L.F.A.M. An application of the TODIM method to the multicriteria rental evaluation of residential properties. Eur. J. Oper. Res. 2009, 193, 204-211. [CrossRef]

24. Moshkovich, H.M.; Gomes, L.F.A.M.; Mechitov, A.I. An integrated multicriteria decision-making approach to reale state evaluation: Case of the todim method. Pesqui. Oper. 2011, 31, 3-20. [CrossRef]

25. Passos, A.C.; Teixeira, M.G.; Garcia, K.C.; Cardoso, A.M.; Gomes, L.F.A.M. Using the TODIM-FSE method as a decision-making support methodology for oil spill response. Comput. Oper. Res. 2014, 42, 40-48. [CrossRef]

26. Tseng, M.-L.; Lin, Y.-H.; Tan, K.; Chen, R.-H.; Chen, Y.-H. Using TODIM to evaluate green supply chain practices under uncertainty. Appl. Math. Model. 2014, 38, 2983-2995. [CrossRef]

27. Gomes, L.F.A.M.; Machado, M.A.S.; Rangel, L.A.D. Behavioral multi-criteria decision analysis: The TODIM method with criteria interactions. Ann. Oper. Res. 2013, 211, 531-548. [CrossRef]

28. Krohling, R.A.; de Souza, T.T.M. Combining prospect theory and fuzzy numbers to multi-criteria decision making. Expert Syst. Appl. 2012, 39, 11487-11493. [CrossRef] 
29. Fan, Z.-P.; Zhang, X.; Chen, F.-D.; Liu, Y. Extended TODIM method for hybrid multiple attribute decision making problems. Knowl. Based Syst. 2013, 42, 40-48. [CrossRef]

30. Lourenzutti, R.; Krohling, R.A. A study of TODIM in a intuitionistic fuzzy and random environment. Expert Syst. Appl. 2013, 40, 6459-6468. [CrossRef]

31. Lourenzutti, R.; Krohling, R.A. The Hellinger distance in multicriteria decision making: An illustration to the TOPSIS and TODIM methods. Expert Syst. Appl. 2014, 41, 4414-4421. [CrossRef]

32. Zhang, W.; Ju, Y.; Gomes, L.F.A.M. The SMAA-TODIM approach: Modeling of preferences and a robustness analysis framework. Comput. Ind. Eng. 2017, 114, 130-141. [CrossRef]

33. Qin, J.; Liu, X.; Pedrycz, W. An extended TODIM multi-criteria group decision making method for green supplier selection in interval type-2 fuzzy environment. Eur. J. Oper. Res. 2017, 258, 626-638. [CrossRef]

34. Beg, I.; Rashid, T. TOPSIS for hesitant fuzzy linguistic term sets. Int. J. Intell. Syst. 2013, 28, $1162-1171$. [CrossRef]

35. Wei, C.; Zhao, N.; Tang, X. A novel linguistic group decision-making model based on extended hesitant fuzzy linguistic term sets. Int. J. Uncertain. Fuzziness Knowl. Based Syst. 2015, 23, 379-398. [CrossRef]

36. Chen, S.M.; Hong, J.A. Multicriteria linguistic decision making based on hesitant fuzzy linguistic term sets and the aggregation of fuzzy sets. Inf. Sci. 2014, 286, 63-74. [CrossRef]

37. Riera, J.V.; Massanet, S.; Herrera-Viedma, E.; Torrens, J. Some interesting properties of the fuzzy linguistic model based on discrete fuzzy numbers to manage hesitant fuzzy linguistic information. Appl. Soft Comput. 2015, 36, 383-391. [CrossRef]

38. Liao, H.; Xu, Z.; Zeng, X.J. Hesitant fuzzy linguistic VIKOR method and its application in qualitative multiple criteria decision making. IEEE Trans. Fuzzy Syst. 2014, 23, 1343-1355. [CrossRef]

39. Liu, H.; Rodríguez, R.M. A fuzzy envelope for hesitant fuzzy linguistic term set and its application to multicriteria decision making. Inf. Sci. 2014, 258, 220-238. [CrossRef]

40. Wang, J.; Wang, J.-Q.; Zhang, H.-Y.; Chen, X.-H. Multi-criteria decision-making based on hesitant fuzzy linguistic term sets: An outranking approach. Knowl. Based Syst. 2015, 86, 224-236. [CrossRef]

41. Wang, J.-Q.; Wang, J.; Chen, Q.-H.; Zhang, H.-Y.; Chen, X.-H. An outranking approach for multi-criteria decision-making with hesitant fuzzy linguistic term sets. Inf. Sci. 2014, 280, 338-351. [CrossRef]

42. Wang, J.; Wang, J.-Q.; Zhang, H.-Y. A likelihood-based TODIM approach based on multi-hesitant fuzzy linguistic information for evaluation in logistics outsourcing. Comput. Ind. Eng. 2016, 99, 287-299. [CrossRef]

43. Yu, W.; Zhang, Z.; Zhong, Q.; Sun, L. Extended TODIM for multi-criteria group decision making based on unbalanced hesitant fuzzy linguistic term sets. Comput. Ind. Eng. 2017, 114, 316-328. [CrossRef]

44. Wei, C.; Ren, Z.; Rodríguez, R.M. A hesitant fuzzy linguistic TODIM method based on a score function. Int. J. Comput. Intell. Syst. 2015, 8, 701-712. [CrossRef]

45. Xia, M.; Xu, Z. Hesitant fuzzy information aggregation in decision making. Int. J. Approx. Reason. 2011, 52, 395-407. [CrossRef]

46. Rodriguez, R.M.; Martinez, L.; Herrera, F. Hesitant fuzzy linguistic term sets for decision making. IEEE Trans. Fuzzy Syst. 2011, 20, 109-119. [CrossRef]

47. Liao, H.; Qin, R.; Gao, C.; Wu, X.; Hafezalkotob, A.; Herrera, F. Score-HeDLiSF: A score function of hesitant fuzzy linguistic term set based on hesitant degrees and linguistic scale functions: An application to unbalanced hesitant fuzzy linguistic MULTIMOORA. Inf. Fusion 2019, 48, 39-54. [CrossRef]

48. Gou, X.; Xu, Z.; Liao, H. Multiple criteria decision making based on Bonferroni means with hesitant fuzzy linguistic information. Soft Comput. 2017, 21, 6515-6529. [CrossRef]

49. Zhang, Z.; Lin, J.; Miao, R.; Zhou, L. Novel distance and similarity measures on hesitant fuzzy linguistic term sets with application to pattern recognition. J. Intell. Fuzzy Syst. 2019, 37, 2981-2990. [CrossRef]

50. Zhang, Z.; Li, J.; Sun, Y.; Lin, J. Novel distance and similarity measures on hesitant fuzzy linguistic term sets and their application in clustering analysis. IEEE Access 2019, 7, 100231-100242. [CrossRef]

Publisher's Note: MDPI stays neutral with regard to jurisdictional claims in published maps and institutional affiliations. 